Article

\title{
Integrated Transport Efficiency and Its Spatial Convergence in China's Provinces: A Super-SBM DEA Model Considering Undesirable Outputs
}

\author{
Fei Ma, Wenlin Wang *, Qipeng Sun, Fei Liu and Xiaodan Li \\ School of Economics and Management, Chang'an University, Xi'an 710064, China; mafeixa@chd.edu.cn (F.M.); \\ 2016123039@chd.edu.cn (Q.S.); 2016123038@chd.edu.cn (F.L.); 2016123083@chd.edu.cn (X.L.) \\ * Correspondence: 2016123084@chd.edu.cn; Tel.: +86-29-8233-8715
}

Received: 21 August 2018; Accepted: 13 September 2018; Published: 19 September 2018

\begin{abstract}
Undesirable outputs, such as carbon emissions and loss of property due to traffic accidents, hold great significance for the sustainable development of the transport industry. In this study, we applied a super-efficiency data envelopment analysis model with a slack-based measure (Super-SBM DEA) considering undesirable outputs to measure the integrated transport efficiency (ITE) of 31 provinces in China during the period of 2009-2016. Following this, we used a spatial autocorrelation model to test and verify the spatial autocorrelation of the ITEs at the level of the 31 provinces, and further to explore the aggregating features. Finally, considering the spatial effects that emerged, we constructed a $\beta$-convergence model to analyze the convergence characteristics of China's ITEs and investigate its conditional factors. The research results show that the average ITE demonstrated a linear growth trend; the effective decision-making units (the ITE value was greater than 1) are only 11 provinces, accounting for about 35\% by 2016. The mean of ITEs was also found to present a law of decreasing order of Eastern, Central and Western Zones. However, the Central Zone and Western Zone have a better efficiency improvement trend compared to the Eastern Zone. The Moran's I index was bigger than zero, indicating that the ITEs formed a spatial autocorrelation phenomenon. The Moran scatter plots further showed that the provincial ITEs mainly followed the patterns of high-high, high-low and low-low aggregation. The ITE of the 31 provinces was found to have a clear absolute $\beta$-convergence and conditional $\beta$-convergence characteristics. Moreover, the level of economic development, household per capita traffic consumption, transport industry scale, technology advancement and transport intensity were all seen to have an important impact on the convergence of integrated transport efficiency. It is hoped that the findings of this study may contribute further insights and practical knowledge to effectively measuring the development level of China's integrated transport efficiency, and to understanding future changes in the ITE gap among Chinese provinces.
\end{abstract}

Keywords: integrated transport efficiency; undesirable outputs; Super-SBM DEA; spatial convergence

\section{Introduction}

The development of the transport industry has been a significant feature in China over past decades. Transport not only plays a major role in the development of the national economy but is also a key element affecting national production and distribution in all aspects [1]. Improving the integrated efficiency of transport thus has great significance for improving the country's regional economic development and regional accessibility, optimizing the allocation of transport resources, and achieving the goal of strengthening the country's communications systems. Integrated transport efficiency (ITE), a ratio of the actual output elements to the input of transport resources, reflects the 
operational status and development potential of the transport system. This not only provides an important basis for measuring the development level of transport in a country or region, but also an important reflection on the rational allocation of transport resources [2]. According to statistical data, the traffic volume of China's transport industry increased at an average rate of $4.75 \%$ from 1978 to 2012. This growth rate lagged behind that of the railway construction industry $(59.61 \%)$, employment (51.13\%), fixed assets investment (79.5\%) and energy consumption (37.82\%) in the same period. From this, it can be deduced that there exists a mismatch between transport outputs and the inputs of human capital, materials and energy [3]. At present, China is in a critical period of building a transport powerhouse, and China's 13th Five-Year Plan proposed to build an integrated transport system that is safe, convenient, efficient and green by 2020. However, China's integrated transport still has a problem that the construction of transport hubs is relatively backward, and the traffic safety situation is still grim. Besides, there are continuous shortage of resource and energy constraints in China. Therefore, it is necessary to undertake a scientific evaluation of the country's ITE to promote the integrated transport, and strengthen sustainable transport development.

Transport is a key factor affecting economic and social development of each province in China. However, there are significant differences between the development levels of transport industry among China's provinces because of the disparities in regional economic development and imbalanced resource distribution. An evaluation of transport efficiency is thus conducive to promoting the efficient flow of transport resources and optimal allocation across these regions. Moreover, given that transport plays an important role in promoting regional development and enabling various resource elements to flow between the provinces, it is necessary to consider the relationship of spatial adjacency to study regional integrated transport efficiency. At present, China has vigorously promoted a coordinated regional development strategy, emphasizing the promotion of the free factors distribution and narrowing the regional disparities. Therefore, it is necessary also to undertake an examination of spatial convergence to understand the changing trends in China's regional transport efficiency.

In the context of sustainable transport and regional coordinated development, this study applies a super-efficiency data envelopment analysis model with a slack-based measure (Super-SBM DEA) considering undesirable outputs to measure the integrated transport efficiency (ITE). Furthermore, according to the administrative divisions of the People's Republic of China in provincial level, the spatial $\beta$-convergence model that consider the spatial effect was subsequently constructed and the convergence characteristics of the integrated transport efficiency of these 31 provinces were further investigated. At the same time, the influence of external condition variables on the convergence of provincial transport efficiency was analyzed by examining conditional $\beta$-convergence. Finally, we explored the gap of regional transport efficiency and its dynamic trend. The purpose of this study was to provide a theoretical basis for recommending an optimal allocation of transport resources and narrowing the ITE gap among 31 provinces in China.

The remainder of this paper is organized as follows. The literature review is presented in Section 2. Section 3 briefly introduces the theoretical model and method. Section 4 presents the empirical analysis, including the selection and pre-processing of the statistical index and data source, and the results analysis. Section 5 put forward the conclusions and policy implications.

\section{Literature Review}

The study of transport efficiency first emerged in the mid-to-late 1970s and mainly focused on Western countries [4,5]. To date, scholars have achieved rich results in studies on transport efficiency [6-10], and the current studies tend to be conducted from two research perspectives. The first is the study of the technical efficiency of different transport modes. For example, Barnum et al. calculated the technical efficiency of different public transport types and put forward the way of improving transport efficiency in metropolitan areas [11]. Carlucci et al. analyzed the general technical, pure technical and scale efficiency of 34 Italian airports by means of the Data Envelopment Analysis (DEA) method [12]. The DEA-BCC model was applied to evaluate the effectiveness of highway 
transport efficiency in the Yangtze River Delta Region, and further to analyze the problems of non-DEA effective units from the perspective of input redundancy and output insufficiency, respectively [13]. Traditional DEA and the Malmquist index model were used to measure water transport efficiency in the Yangtze River Economic Zone [14]. Joanna et al. constructed a DEA model to measure the efficiency of selected European countries in terms of the transport accessibility of freight transport by road and rail [15]. Jain et al. studied the technical efficiency of the urban rail transit system using DEA [16]. A two-stage combination of Stochastic Data Envelopment Analysis was used to analyze urban transportation efficiency in 285 cities of the world [17]. Tavassoli et al. proposed a novel slack-based measure network DEA to measure the technical efficiency of airlines [18]. Fu and Jenelius evaluated the transport efficiency of off-peak urban goods deliveries, studying transport efficiency in a number of dimensions including driving efficiency, delivery reliability, energy efficiency and service efficiency [19]. The two-stage DEA was used to assess the efficiency of Brazilian rail freight transport between 2010 and 2014 [20].

The second evaluation facet has mainly focused on the environmental and energy efficiency of transport [21-23]. For example, a non-radial DEA model was used to measure the regional energy and environmental efficiency of China's transport sector, considering undesirable outputs [24]. A parallel slack-based measure model (SBM) was proposed and used to evaluate the overall environmental efficiency of the land transport sector, individual environmental efficiencies of railway transport, and highway transport subsectors [25]. Another study examined the energy efficiency of China's transport sector from 2003 to 2009 using a DEA approach [26]. Song et al. combined the super-efficiency slack-based measure model (Super-SBM DEA) to calculate the environmental efficiencies of highway transport systems in different regions of China [27], with a key focus on the problems of energy consumption and pollutant emissions of highway transport.

As highlighted by the studies reviewed, thus far, the most common method used in transport efficiency research is DEA - an effective, non-parametric method favored by numerous scholars [28-31]. The reason DEA is so frequently used to analyze efficiency is that it does not require any prior assumptions to be made about the underlying functional relationships between inputs and outputs [32-34]. The traditional DEA model has also been gradually improved and innovated upon. For example, a slack-based measure DEA model was used to analyze the efficiency of China's transport sector in 2009 [35]. Based on the DEA method, another study assessed road transport efficiency by using the value added of the road transport industry and passenger and cargo turnover as outputs, finding clear regional differences in the efficiency of road transport [36]. Other research has also taken the added value of the road transport industry, passenger volume, freight and turnover as outputs to measure road transport efficiency [37]. Working from an input-output perspective, $\mathrm{Wu}$ et al. used the three-stage DEA model to measure the integrated transport efficiency of China's provinces in 2013 and further analyzed the spatial cluster characteristics, which mainly focuses on the impact of random environments on efficiency [38].

However, all of the aforementioned studies have ignored the fact that transport not only brings significant economic benefits to society but can also lead to environmental and social problems (e.g., excessive energy consumption, air pollution, carbon emissions, accidents and congestion) [39].

According to the relevant statistics, the total energy consumption required by the global transport system rose from $23 \%$ in 1973 to $28 \%$ in 2012. Moreover, in 2050, as much as $30-50 \%$ of total $\mathrm{CO}_{2}$ emissions are predicted to come from the transport sector [40]. With the rapid growth of energy consumption and increasing emissions of pollutants brought about by transport, numerous scholars have paid much attention to the negative effects of undesirable outputs. For instance, Wei et al. analyzed urban transport efficiency in 285 cities across the world from 2009 to 2012, exploring efficiency levels with a focus on productive capacity slacks including two undesirable output indicators [41]. $\mathrm{Li}$ et al. attempted to evaluate regional integrated transport efficiency and explored the factors influencing transport efficiency in China, in particular considering undesirable outputs during the period 1995-2012 [42]. However, this study merely incorporated $\mathrm{CO}_{2}$ emissions as an undesirable 
output and ignored other undesirable transport outputs. Yang et al. evaluated the efficiency of road transport in China's provinces using the number of traffic accidents and carbon dioxide emissions from the energy consumption of road transport as undesired outputs, finding the level of road transport efficiency to be generally low [43]. The limitation of this study is that it only discussed the efficiency of road transport, ignoring the measurement of the efficiency of other modes of transport. With advances being made in the construction of China's transport powerhouse, the development of high-speed railways and the gradual improvement of the country's road network infrastructure have grown increasingly rapidly. Therefore, a measurement of transport efficiency should consider all modes of transport.

Combining the above analysis, some scholars have introduced undesirable outputs into their DEA models for the purpose of evaluating transport efficiency. However, there still exist certain deficiencies in the selection of indicators and evaluation methods that make it impossible to measure the efficiency of transport resource allocation accurately. In addition, the aforementioned studies have mostly focused on evaluating the efficiency of certain types of transport, and ignore the efficiency measuring of integrated transport system. To date, there have been few significant attempts to study the effect of differences in the efficiency of various transport modes over time in different areas, and the impact of the geographic spatial effect on this efficiency. In fact, some studies have considered the convergence of spatial effects in other fields of research. For example, spatial panel data models were utilized to investigate the stochastic convergence and $\beta$-convergence of carbon intensity [44]. Xiao et al. analyzed the convergence of innovation capabilities on different space-scales by applying the spatial panel of the $\beta$-convergence model [45]. In addition, studies of convergence in this context have also included economic growth [46] and per capita energy consumption [47], among other factors. These studies of convergence provide a methodology reference for considering the convergence of spatial effects.

Integrated transport efficiency is a key performance metric for measuring the development of the transport industry. Based on the literature reviewed in the current section, this study selected transport carbon emissions and loss of property due to traffic accidents as undesirable outputs, and applied Super-SBM DEA to measure the integrated transport efficiency of 31 provinces in China during 2009-2016 and further explore its spatial convergence.

\section{Models and Methods}

\subsection{Super-Efficiency Data Envelopment Analysis Model with Slack-Based Measure Considering Undesirable Outputs}

Data Envelopment Analysis (DEA) was first proposed by Charnes et al. in 1978 [48]. It is a non-parametric efficiency evaluation method that uses a mathematical planning model to calculate the distance between each Decision Making Unit (DMU) and the production frontier consisting of the best performing DMUs in practice, and further to calculate the efficiency score of each DMU. However, the traditional DEA model cannot deal with efficiency issues that include undesirable outputs. In 2001, a Slacks-Basic Measure (SBM) model based on relaxation measures was proposed by Tone [49], which can solve the efficiency evaluation problem including undesired outputs. The SBM method, which is non-radial, can deal with input/output slacks directly and eliminate the radial and oriented deviation [50].

In efficiency evaluation research field, there appear certain DMUs that simultaneously have the full efficient status (value $=1$ ). To distinguish between the efficiency levels of these efficient DMUs, the Super-efficiency DEA was proposed by Anderson-a model that aims to make efficiency evaluation results more detailed and accurate [51]. In this study, we mainly considered the impact of the undesirable outputs of transport carbon emissions and traffic accident property losses, so the SBM model is very suitable and was chosen to calculate the integrated transport efficiency of 31 provinces in China. Besides, Super-efficiency DEA model can help to distinguish the efficiency levels among provinces. Accordingly, combining the SBM model and Super-efficiency DEA model, the Super-SBM 
DEA model was adopted. The Super-SBM DEA model based on undesirable outputs was constructed as Formula (1):

$$
\begin{gathered}
\min I T E_{k}=\frac{1+\frac{1}{m} \sum_{i=1}^{m} s_{i}^{-} / x_{i k}}{1-\frac{1}{q_{1}+q_{2}}\left(\sum_{r=1}^{q_{1}} s_{r}^{+} / y_{r k}^{a}+\sum_{t=1}^{q_{2}} s_{t}^{-} / y_{t k}^{b}\right)} \\
\text { s.t }\left\{\begin{array}{c}
\sum_{j=1, j \neq k}^{n} x_{i j} \lambda_{j}-s_{i}^{-} \leq x_{i k} \\
\sum_{j=1, j \neq k}^{n} y_{r j}^{a} \lambda_{j}+s_{r}^{+} \geq y_{r k}^{a} \\
\sum_{j=1, j \neq k}^{n} y_{t k}^{b} \lambda_{j}-s_{t}^{-} \leq y_{t k}^{b} \\
1-\frac{1}{q_{1}+q_{2}}\left(\sum_{r=1}^{q_{1}} s_{r}^{+} / y_{r k}^{a}+\sum_{t=1}^{q_{2}} s_{t}^{-} / y_{t k}^{b}\right)>0 \lambda, s^{-}, s^{+} \geq 0 \\
k=1,2,3 \cdots 31 ; \quad i=1,2, \cdots m ; \\
r=1,2,3 \cdots q_{1} ; \quad t=1,2,3 \cdots q_{2}
\end{array}\right.
\end{gathered}
$$

where $I T E_{k}$ is the value of the integrated transport efficiency of $D M U_{k} ; m, q_{1}$ and $q_{2}$ represent the number of inputs, desirable outputs and undesirable outputs, respectively; $x_{i k}, y_{r k}$ and $z_{t k}$ represent the $i$ th input, $r$ th desirable output, and $t$ th undesirable output of $D M U_{k}$, respectively; $s_{i}^{-}$is the redundant variable for the input; $s_{r}^{+}$is the slack variable for the desirable output; $s_{t}^{-}$is the redundant variable for the undesirable output; $a$ and $b$ are used to denote the variables of the desirable and undesirable outputs, respectively; $y_{r k}^{a}$ represent the $r$ th desirable output of $D M U_{k}$; and $y_{t k}^{b}$ represents the $t$ th undesirable output of $D M U_{k}$.

\subsection{Spatial Autocorrelation Model}

Neglecting spatial autocorrelation problems may lead to errors in the estimation of convergence analysis considering spatial effects [52]. Therefore, it is necessary for us first to use the Moran's I index to test the spatial autocorrelation of the integrated transport efficiency of China's provinces.

Global spatial autocorrelation mainly reflects the overall similarity of spatially adjacent units in the entire research area [53]. In this study, Moran's I index was used to analyze the spatial autocorrelation of integrated transport efficiency among 31 provinces in China. It was also used to measure whether there exists a related influence on integrated transport efficiency between neighboring provinces. The range of Moran's I value is $[-1,1]$. The closer the value of the index is to 1 , the greater the positive spatial autocorrelation is. Conversely, when the Moran's I index is closer to -1 , it indicates a spatial negative autocorrelation. When the Moran's I index is close to 0 , it shows that the subjects may be randomly distributed in space [54]. The specific calculation method used was as follows:

$$
I_{I T E}=\frac{n \sum_{i} \sum_{j} w_{i j}(I T E-\overline{I T E})\left(I T E_{j}-\overline{I T E}\right)}{\left(\sum_{i} \sum_{j} w_{i j}\right) \sum_{i}\left(I T E_{i}-\overline{I T E}\right)^{2}} \quad(i, j=1,2, \ldots, 31)
$$

where $I T E_{i}$ and $I T E_{j}$ represent transport efficiency in regions $i$ and $j$, respectively; $\overline{I T E}$ represents the average value of regional integrated transport efficiency; $n$ represents the number of regional units; and $W$ is the space weight matrix, reflecting the spatial adjacency of regions $i$ and $j$. Due to the irregularity of the boundaries of each provincial unit, we chose the "queen" adjacency method to set the spatial weight matrix. In other words, there is a shared edge or a shared point in the adjacent area. Using binary weights, when $i$ and $j$ regions are adjacent, the weight of $w_{i j}$ is 1 ; otherwise, it is 0 . The specific formula applied was as follows: 


$$
\begin{gathered}
W=\left[\begin{array}{cccc}
w_{11} & w_{12} & \cdots & w_{1 n} \\
w_{21} & w_{22} & \cdots & w_{2 n} \\
\cdots & \cdots & \cdots & \cdots \\
w_{n 1} & w_{n 2} & \cdots & w_{n n}
\end{array}\right] \\
w_{i j}=\left\{\begin{array}{l}
1, \text { region i and region } j \text { are adjacent } \\
0, \text { region i and region } j \text { are not adjacent }
\end{array}\right.
\end{gathered}
$$

To ensure the accuracy of the global Moran's I index, it is necessary to apply the Z-test to further test the significance of the spatial autocorrelation. The test formula is as follows:

$$
Z_{I T E}=\frac{I-E\left(I_{I T E}\right)}{\sqrt{V\left(I_{I T E}\right)}}
$$

where $E\left(I_{I T E}\right)=1 /(n-1)$ indicates the expected value; $V\left(I_{I T E}\right)=E\left(I_{I T E}^{2}\right)-E\left(I_{I T E}\right)^{2}$ represents the standard deviation.

\subsection{Spatial Convergence Model}

To explore whether the gaps in the integrated transport efficiency between the studied Chinese provinces was widening or narrowing, this study introduced a convergence analysis. Convergence refers to the process of the difference between the related indicators of two or more research objects growing smaller over time. This is an important economic theory that was originally applied to investigate the convergence of per capita income across different regions and countries.

$\beta$-convergence deems that a region with a low value has a higher growth rate than the region with a high value, whereby, eventually, the low value region will catch up with the high value region and a stable growth rate will be achieved across the two regions. $\beta$-convergence includes the absolute $\beta$-convergence and the conditional $\beta$-convergence. The absolute $\beta$-convergence considers that the convergence of all units is not affected by other factors, but only depends on the initial level of efficiency and will eventually reach the same stable state. The conditional $\beta$-convergence considers that other external factors will affect the convergence, thus making each DMU develop according to development characteristics and along the stable state of different path items. Based on imbalanced development and the significant differences between the integrated transport efficiency of China's provinces, the absolute $\beta$-convergence was used to analyze whether the growth rate of integrated transport efficiency in each province converges, and whether there exists a trend of regions with lagging transport efficiency catching up with other regions with more advanced efficiency. The conditional $\beta$-convergence takes into account the external factors affecting integrated transport in each province, and specifically analyzes the convergence of integrated transport efficiency across the provinces under the influence of external factors.

Most previous research has used the traditional $\beta$-convergence to study convergence, ignoring the influence of the spatial unit characteristics on the convergence. In recent years, spatial econometric models have been developed and applied to many fields, as these take the spatial dependence and the spatial correlation between regions fully into account in a developing society. Therefore, we explored the convergence characteristics of integrated transport efficiency in China's provinces by considering spatial effect, constructing a spatial absolute $\beta$-convergence model and a conditional $\beta$-convergence model for the purposes of this study. The model is described as follows:

$$
\begin{gathered}
\operatorname{Ln}\left(I T E_{i, t} / I T E_{i, t-1}\right)=\alpha+\beta \operatorname{LnITE} E_{i, t}+\lambda \operatorname{Ln}\left(\operatorname{ITE}_{i, t} / \operatorname{ITE} E_{i, t-1}\right)+\varepsilon \quad \varepsilon \sim\left(0, \sigma^{2}\right) \\
\operatorname{Ln}\left(\operatorname{ITE}_{i, t} / \operatorname{ITE}_{i, t-1}\right)=\alpha+\beta \operatorname{LnITE} E_{i, t}+\lambda \operatorname{Ln}\left(\operatorname{ITE}_{i, t} / \operatorname{ITE}_{i, t-1}\right)+C_{k} \operatorname{LnX} X_{k}+\varepsilon \quad \varepsilon \sim\left(0, \sigma^{2}\right) \\
\operatorname{Ln}\left(\operatorname{ITE}_{i, t} / \operatorname{ITE} E_{i, t-1}\right)=\alpha+\beta \operatorname{LnITE} E_{i, t}+\gamma W \varepsilon_{i, t-1}+\omega \omega \sim\left(0, \sigma^{2} I\right)
\end{gathered}
$$




$$
\operatorname{Ln}\left(T E_{i, t} / T E_{i, t-1}\right)=\alpha+\beta \operatorname{LnTE} E_{i, t}+C_{k} \operatorname{LnX} X_{k}+\gamma W \varepsilon_{i, t-1}+\omega \quad \omega \sim\left(0, \sigma^{2} I\right)
$$

where $I T E_{i, t}$ and $I T E_{i, t-1}$ represent the values of integrated transport efficiency of the th year and the $(t-1)$ th year for the $i$ th province, respectively. $\lambda$ represents the spatial autoregressive coefficient, reflecting the size of the spatial interactions in each region. $\lambda \operatorname{Ln}\left(I T E_{i, t} / I T E_{i, t-1}\right)$ represents the spatial lag term of the interpreted variable. $W$ represents the spatial weight matrix. $\varepsilon$ and $\varepsilon_{i, t-1}$ are random error terms. $Y$ and $\omega$ are random variables that reflect the correlation between regression residual space and spatial correlation, respectively. $X_{k}$ is the control variable of the conditional convergence analysis. $C_{k}$ is the parameter of the condition variable that needs to be estimated. $\alpha$ is a constant term and $\beta$ is used to measure the convergence of regional transport efficiency. When $\beta$ is less than 0 , it indicates that that particular province contains a convergence with regard to integrated transport efficiency. In the opposite case, this convergence does not exist.

Formulas (6) and (8) represent the Spatial Lag Model (SLM) and Spatial Error Model (SEM) of the absolute $\beta$-convergence, respectively. Formulas (7) and (9) represent the SLM and SEM of the conditional $\beta$-convergence, respectively. By setting the dependent variable in the regression model of spatial autocorrelation, the SLM model was used to study that a province is affected by spillover effect of its adjacent province, i.e., the degree of influence of the impact of the variable error of each province's neighbors. SEM highlighted that the interactions between the provinces were comprised of the different differences in their relative position, and measured the degree of influence of the impact of the variable error of each province's neighbors.

If the study object was found to have convergent characteristics, we were further able to calculate the corresponding convergence speed $\theta$, and the half life cycle $\tau$, i.e., the time taken by provinces with a low level of integrated transport efficiency to catch up with provinces that had high integrated transport efficiency. The specific calculation formula was as follows:

$$
\begin{gathered}
\theta=-\frac{\ln (1+\bar{\beta})}{T} \\
\tau=\frac{\ln 2}{\theta}
\end{gathered}
$$

where $T$ represents the time length of the study and $\bar{\beta}$ is the estimated value of the convergence coefficient.

\section{Empirical Analysis}

\subsection{Evaluation Index Selection and Data Sources}

This study focuses on the integrated transport efficiency of China's regions based on capital, manpower and resource inputs. Considering the limitations of data availability, we further selected three indexes as the inputs and five indexes as the outputs to evaluate the integrated transport efficiency of 31 provinces in China during 2009-2016, as shown in Figure 1.

INPUTS

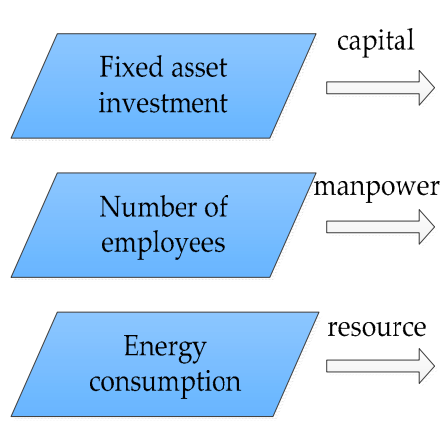

METHOD

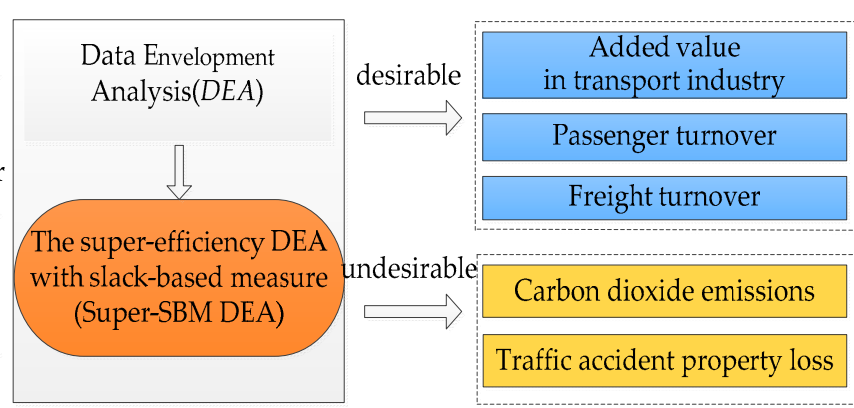

\section{OUTPUTS}

Figure 1. Super-efficiency slack-based measure model. 
The amount of fixed capital investment in transport and the number of employees were used as the capital and the manpower input values, respectively. The volume of energy consumed by transport was used as the energy input value; this is one of the major inputs in many production and related processes, and is especially needed in the transport sector. The value added by the transport industry, passenger turnover and freight turnover were selected as the desirable outputs and reflected production values. The volume of carbon dioxide emissions and traffic accident property losses were selected as the undesirable outputs.

The fixed assets investment, number of employees, added value in transport industry, passenger turnover, freight turnover and traffic accident property loss were directly derived from the China Statistical Yearbook [55] (2009-2016), and the energy consumption indicator was derived from the China Energy Statistical Yearbook [56] (2009-2016). However, there were no official statistics available on regional carbon dioxide emissions in China. Therefore, transport $\mathrm{CO}_{2}$ emissions were estimated using the method provided by the Intergovernmental Panel on Climate Change (IPCC) [57]. The specific formula is as follows:

$$
C=\sum_{i} C_{i}=\sum_{i} E_{i} F_{i} \quad(i=1,2,3 \cdots \cdots 8)
$$

where $C$ represents total carbon emissions from various types of energy and $C_{i}$ refers to carbon emissions from category $i$ energy. $E_{i}$ and $F_{i}$ represent energy consumption of category $i$ and the $\mathrm{CO}_{2}$ emission factor, respectively. The standard coal coefficient and $\mathrm{CO}_{2}$ emission factor for each type of energy conversion are shown in Table 1.

Table 1. Standard coal coefficient and $\mathrm{CO}_{2}$ emission factor.

\begin{tabular}{|c|c|c|c|c|}
\hline Energy Type & Raw Coal & Coke & Crude & Fuel Oil \\
\hline $\begin{array}{l}\text { Standard Coal Conversion Factor } \\
\qquad\left(\mathrm{kgce} / \mathrm{kg} \text { or } \mathrm{m}^{3}\right)\end{array}$ & 0.7143 & 0.9714 & 1.4286 & 1.4286 \\
\hline $\begin{array}{l}\mathrm{CO}_{2} \text { emission factor } \\
\left(\mathrm{kg} \mathrm{CO}_{2} / \mathrm{kg} \text { or } \mathrm{m}^{3}\right)\end{array}$ & 0.7559 & 0.8550 & 0.5857 & 0.6185 \\
\hline Energy Type & Petrol & Kerosene & Diesel & $\begin{array}{c}\text { Natural } \\
\text { Gas }\end{array}$ \\
\hline $\begin{array}{l}\text { Standard Coal Conversion Factor } \\
\qquad\left(\mathrm{kgce} / \mathrm{kg} \text { or } \mathrm{m}^{3}\right)\end{array}$ & 1.4714 & 1.4714 & 1.4571 & 1.4286 \\
\hline $\begin{array}{l}\mathrm{CO}_{2} \text { emission factor } \\
\left(\mathrm{kg} \mathrm{CO}_{2} / \mathrm{kg} \text { or } \mathrm{m}^{3}\right)\end{array}$ & 2.93 & 0.5714 & 0.5921 & 0.4483 \\
\hline
\end{tabular}

Note: Standard coal conversion factors of energy were derived from the China Energy Statistical Yearbook. $\mathrm{CO}_{2}$ emission factors were from the China Energy Statistical Yearbook and National Greenhouse Gas Emission Inventory Guide (2006).

The calculation of carbon dioxide emissions by the integrated transport of the 31 studied regions of China is shown in Figure 2. In recent years, carbon emissions as a negative external transport output has shown a significant growth trend, with emissions reaching a peak in 2015. Although China's transport carbon emissions declined in 2016, in this year, emissions were still $28.7 \%$ higher than in 2009. Carbon emissions are one of the undesirable outputs of transport which seriously restrict improvements to integrated transport efficiency. Moreover, according to the changing trend that can be observed in Figure 2, transport carbon emissions are predicted to continue increasing to some extent.

The statistical descriptions of the indexes are shown in Table 2. 


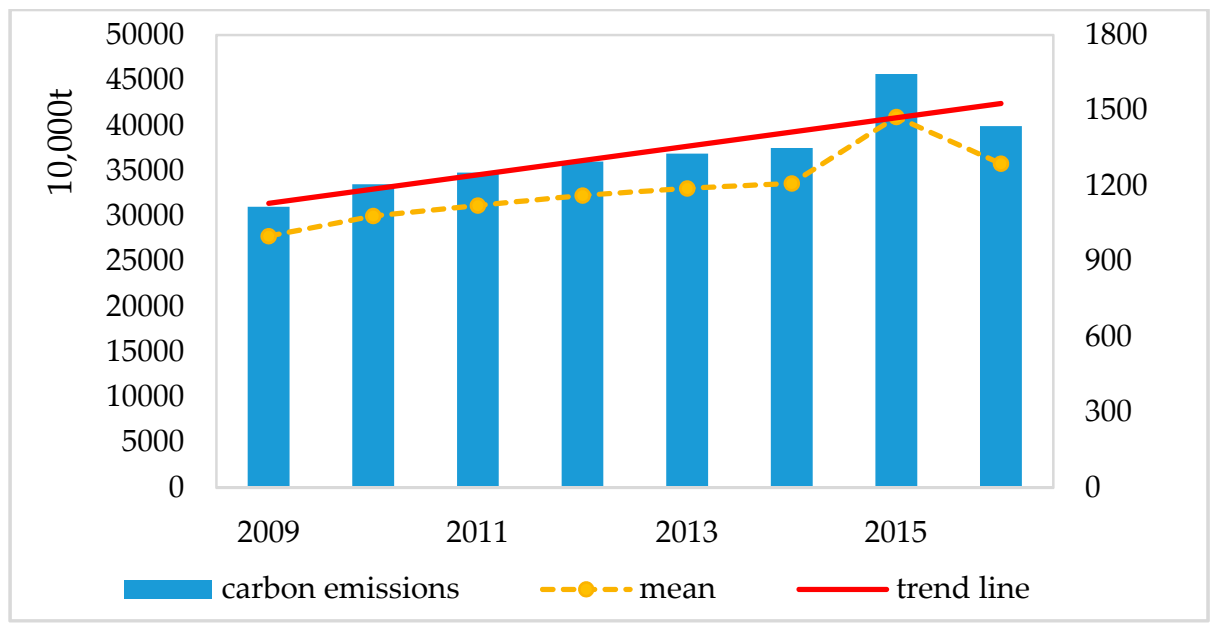

Figure 2. Total carbon emissions of integrated transport.

Table 2. The statistical description of input and output indexes.

\begin{tabular}{cccccc}
\hline & Index & Minimal & Maximal & Mean & $\begin{array}{c}\text { Standard } \\
\text { Deviation }\end{array}$ \\
\hline \multirow{2}{*}{ inputs } & Fixed asset investment & 78.89 & 3516.28 & 918.68 & 643.47 \\
& Number of employees & 3290 & 635,533 & $178,217.08$ & $117,576.54$ \\
& Energy consumption & 114.83 & $20,275.60$ & 1656.10 & 3174.61 \\
\hline \multirow{2}{*}{ desirable outputs } & added value in transport industry & 21.19 & 3209.72 & 892.34 & 676.16 \\
& Passenger turnover & 29.98 & 2998.23 & 771.99 & 554.23 \\
& Freight turnover & 35.34 & $21,801.65$ & 4772.51 & 4455.83 \\
\hline \multirow{2}{*}{ undesirable outputs } & Carbon dioxide emissions & 78.08 & $13,787.41$ & 1126.15 & 2158.73 \\
& Traffic accident property loss & 290.54 & $10,726.59$ & 3392.20 & 2255.92 \\
\hline
\end{tabular}

\subsection{Results Analysis and Discussion}

\subsubsection{Evaluation of Integrated Transport Efficiency}

Using Formula (1), we calculated the ITE values from 2009 to 2016 for the 31 provinces, as summarized in Table 3.

Table 3. ITE results from 2009 to 2016.

\begin{tabular}{cccccccccc}
\hline Province & $\mathbf{2 0 0 9}$ & $\mathbf{2 0 1 0}$ & $\mathbf{2 0 1 1}$ & $\mathbf{2 0 1 2}$ & $\mathbf{2 0 1 3}$ & $\mathbf{2 0 1 4}$ & $\mathbf{2 0 1 5}$ & $\mathbf{2 0 1 6}$ & Average ITE \\
\hline Beijing & 0.58 & 0.60 & 0.78 & 0.89 & 0.98 & 1.03 & 1.00 & 1.02 & 0.86 \\
Tianjin & 1.15 & 1.14 & 1.14 & 1.32 & 1.20 & 1.05 & 1.03 & 1.04 & 1.13 \\
Hebei & 1.07 & 1.07 & 1.07 & 1.13 & 1.22 & 1.16 & 1.23 & 1.21 & 1.15 \\
Shanxi & 0.39 & 0.39 & 0.48 & 0.52 & 0.56 & 0.68 & 0.63 & 0.75 & 0.55 \\
Inner Mongolia & 0.84 & 0.73 & 0.93 & 0.95 & 0.87 & 0.83 & 0.90 & 0.84 & 0.86 \\
Liaoning & 0.61 & 0.59 & 0.79 & 0.69 & 0.83 & 0.75 & 0.92 & 0.90 & 0.76 \\
Jilin & 0.58 & 0.49 & 0.56 & 0.54 & 0.65 & 0.61 & 0.66 & 0.73 & 0.60 \\
Heilongjiang & 0.47 & 0.42 & 0.34 & 0.35 & 0.39 & 0.47 & 0.54 & 0.67 & 0.46 \\
Shanghai & 1.19 & 1.28 & 1.26 & 1.20 & 1.28 & 1.30 & 1.24 & 1.25 & 1.25 \\
Jiangsu & 1.05 & 1.06 & 1.04 & 1.02 & 0.98 & 0.87 & 0.93 & 0.87 & 0.98 \\
Zhejiang & 0.59 & 0.64 & 0.51 & 0.57 & 0.61 & 0.65 & 0.58 & 0.79 & 0.62 \\
Anhui & 1.14 & 1.11 & 1.10 & 1.19 & 1.05 & 1.12 & 1.08 & 1.05 & 1.11 \\
Fujian & 0.66 & 0.58 & 0.47 & 0.54 & 0.56 & 0.67 & 0.58 & 0.84 & 0.61 \\
Jiangxi & 1.03 & 1.01 & 0.89 & 0.66 & 0.87 & 0.93 & 1.01 & 1.03 & 0.93 \\
Shandong & 1.09 & 1.01 & 1.02 & 1.05 & 0.78 & 0.64 & 0.79 & 0.83 & 0.90 \\
Henan & 1.03 & 1.07 & 1.13 & 1.09 & 1.08 & 1.09 & 1.07 & 1.06 & 1.08 \\
\hline
\end{tabular}


Table 3. Cont.

\begin{tabular}{cccccccccc}
\hline Province & $\mathbf{2 0 0 9}$ & $\mathbf{2 0 1 0}$ & $\mathbf{2 0 1 1}$ & $\mathbf{2 0 1 2}$ & $\mathbf{2 0 1 3}$ & $\mathbf{2 0 1 4}$ & $\mathbf{2 0 1 5}$ & $\mathbf{2 0 1 6}$ & Average ITE \\
\hline Hubei & 0.36 & 0.41 & 0.44 & 0.49 & 0.49 & 0.57 & 0.61 & 0.73 & 0.51 \\
Hunan & 0.51 & 0.53 & 0.64 & 0.76 & 1.03 & 1.02 & 1.04 & 1.05 & 0.82 \\
Guangdong & 0.65 & 0.56 & 0.65 & 0.69 & 0.63 & 0.74 & 0.73 & 0.86 & 0.69 \\
Guangxi & 0.43 & 0.45 & 0.60 & 0.52 & 0.65 & 0.59 & 0.63 & 0.58 & 0.56 \\
Hainan & 0.54 & 0.53 & 0.59 & 0.61 & 0.58 & 0.54 & 0.57 & 0.65 & 0.58 \\
Chongqing & 1.05 & 1.11 & 1.16 & 1.04 & 1.12 & 1.10 & 1.13 & 1.07 & 1.10 \\
Sichuan & 0.41 & 0.54 & 0.68 & 1.05 & 0.94 & 0.83 & 0.81 & 1.01 & 0.76 \\
Guizhou & 1.01 & 1.04 & 1.02 & 1.03 & 1.03 & 1.01 & 0.98 & 1.02 & 1.02 \\
Yunnan & 0.32 & 0.39 & 0.46 & 0.77 & 0.75 & 0.89 & 0.72 & 0.76 & 0.63 \\
Tibet & 0.11 & 0.12 & 0.13 & 0.13 & 0.24 & 0.18 & 0.21 & 0.22 & 0.17 \\
Shaanxi & 0.45 & 0.54 & 0.59 & 0.64 & 0.78 & 0.82 & 0.88 & 0.92 & 0.70 \\
Gansu & 0.64 & 0.69 & 0.71 & 0.78 & 0.69 & 0.81 & 0.79 & 0.94 & 0.76 \\
Ningxia & 0.32 & 0.34 & 0.40 & 0.39 & 0.53 & 0.58 & 0.65 & 0.69 & 0.49 \\
Qinghai & 0.33 & 0.37 & 0.38 & 0.47 & 0.50 & 0.48 & 0.53 & 0.51 & 0.45 \\
Xinjiang & 0.29 & 0.38 & 0.32 & 0.39 & 0.48 & 0.45 & 0.39 & 0.47 & 0.40 \\
National Avg. ITE & 0.67 & 0.68 & 0.72 & 0.76 & 0.79 & 0.79 & 0.80 & 0.86 & \\
\hline
\end{tabular}

Calculating the results in Table 2, we found that the average ITE of the 31 provinces increased over time in a straight line. However, the number of effective provinces (i.e., ITEs greater than 1) was clearly lacking and only about $22.58 \%$ from the perspective of average ITE. By 2016 , there were only 11 provinces with a transport efficiency value greater than 1, accounting for about $35 \%$. This indicates the need to adjust the amount of investment into the transport resources of each province as well as to improve the effective outputs.

From the perspective of changes in integrated transport efficiency, the ITE values in Beijing, Shanxi, Hubei, Hunan, Yunnan, Shaanxi and Ningxia showed a linear upward trend, reflecting the gradual increase in the effective use of input elements in these regions. Among them, Beijing and Hunan achieved the value of effective decision making units in 2014 and 2013, respectively, reflecting the largest output of input factors. Conversely, the ITE value in Jiangsu began to decline slightly in 2013. One of the main reasons for this was the redundant input of fixed assets investment. The ITE has changed volatilely from 2014 to 2016 in Jiangsu. In addition, the ITE value in Jiangxi manifests the phenomenon of first decreasing and then increasing, with a difference of 0.37 between the minimum and maximum efficiency values. Shandong's ITE also showed a similar change pattern of first decreasing and then increasing. The latter's ITE value fell from its highest of 1.09 down to 0.64 with a rate of decrease of around $42 \%$. In 13 provinces, including Inner Mongolia, Liaoning, Jilin and Zhejiang, integrated transport efficiency showed a fluctuating trend, but with a growth in overall performance. ITE in Tianjin, Hebei, Shanghai, Anhui, Henan and Chongqing performed effectively during the period of 2009-2016, indicating an optimal utilization of input factors, and further reflecting that these provinces have a favorable allocation of transport resources and are able to achieve maximum outputs. Guizhou, located in the southwest of China, has a relatively low level of economic development, but with relatively high transport efficiency. During the eight years covered in the current research, only a slight decline occurred in 2015, but the evaluation of overall integrated transport efficiency in Guizhou proved very optimistic. According to the statistics, Tianjin, Shanghai, Hebei, Anhui, Henan and Chongqing have always maintained efficient ITE. These provinces are role models for development. The province with low ITE should study their resource allocation patterns and improve utilization efficiency. In Qinghai, Ningxia and Xinjiang, integrated transport efficiency was low, but room for ongoing improvement exists for freight output. Jilin and Heilongjiang should increase added value in transport industry to improve the ITE. For Fujian, Hubei and Guangxi, passenger turnover and freight turnover should be improved at the same time to promote efficiency. These regions further emphasize the importance of an appropriate allocation of transport resources, and of finding a solution to the challenges restricting improvements in these areas' integrated transport 
efficiency. For example, in Qinghai Province, which is home to China's largest inland brackish water lake, tourism has developed rapidly in recent years. To provide convenient transport and other tourism-friendly conditions, the investment in fixed assets of the area's transport industry has increased from 12.415 billion yuan in 2009 to 58.992 billion yuan in 2016. This has seen a growth in input of almost five times, while the output increase ratio has been less than 1.5. In addition, the undesirable outputs of transport carbon emissions and property losses due to traffic accidents also exist, which further affect the overall ITE. For example, Beijing, the capital city, should accelerate the reduction of carbon emissions from transport to reach effective.

To demonstrate the integrated efficiency of China's regional transport systems more intuitively, we took 2009, 2011, 2014 and 2016 as research years, and applied ArcGIS software to reflect the changes of ITE in temporal and spatial distribution from the perspective of geographical spatial distribution. As shown in Figure 3, according to the size of the efficiency value, the ITEs are divided into four intervals marked by the different colors. It can be seen that most provinces manifested a trend of improvement with regard to their transport efficiency. The high integrated transport efficiency can be found in the Eastern and Central regions, indicating that transport resources in these areas have advantages such as good geographical locations and favorable economic development conditions. In addition, changes in the distribution of ITE lend themselves to the phenomenon of the super-efficient provinces shifting away from Eastern and Central areas towards Western regions.

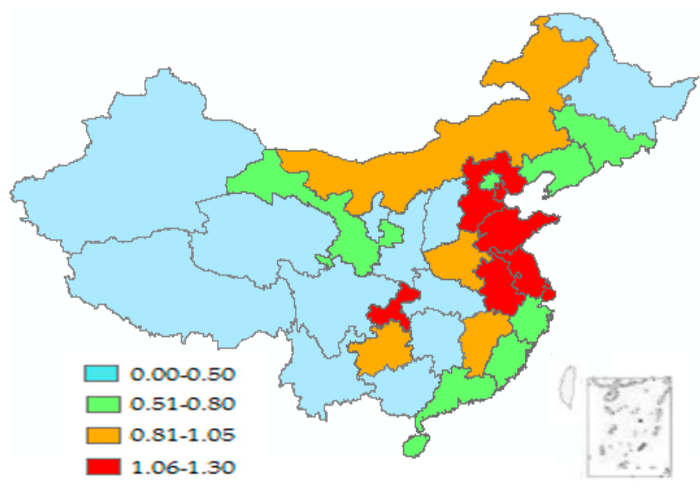

2009

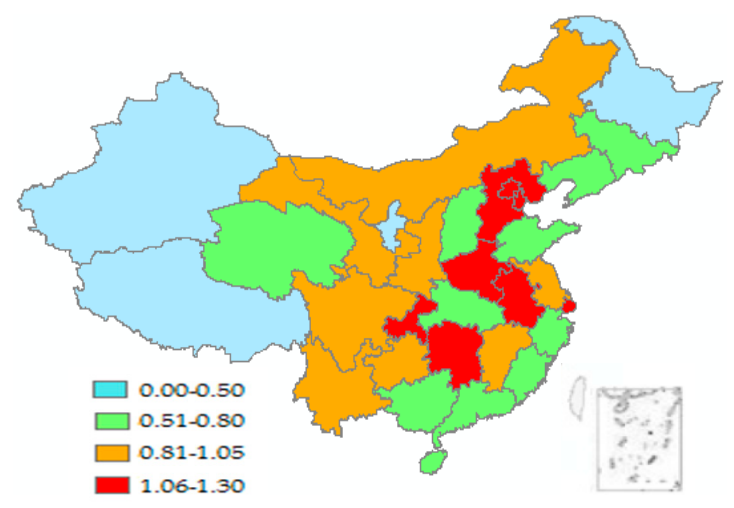

2014

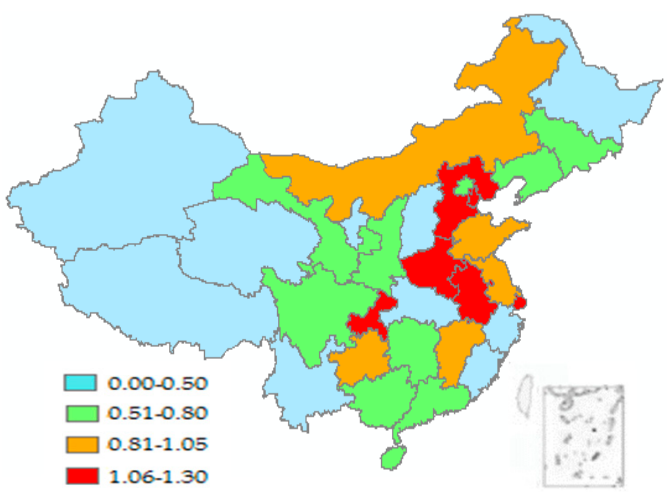

2011

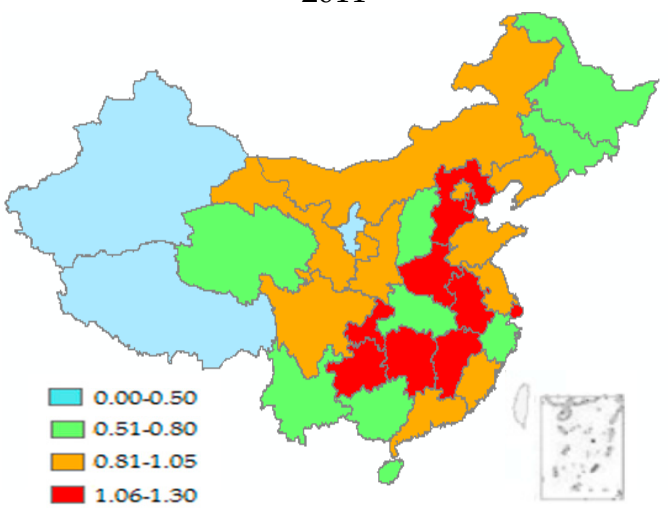

2016

Figure 3. Comparison of spatial and temporal changes in ITE.

Considering the average value of ITE of the 31 provinces from 2009 to 2016, we found it to be distributed in the interval $[0.17,1.25]$. We then divided this average into five categories. When the ITE value was over 1.0 from 2009 to 2016, this indicated that particular region belonged to the category of super-efficient. Subsequent values were divided into relatively efficient, medium-high efficient, low-medium efficient, and inefficient to highlight changes in the ITE of each province during 2009-2016. Figure $4 \mathrm{a}$ shows the change of super ITE values; Figure $4 \mathrm{~b}$ presents the change of relatively efficient 
ITE value; Figure 4c expresses the change of medium-high efficient ITE value; Figure $4 \mathrm{~d}$ shows the change of low-medium efficient ITE value; and Figure 4e presents the change of inefficient ITE value. In this figure, we can see the changes of ITE for each province during 2009-2016.

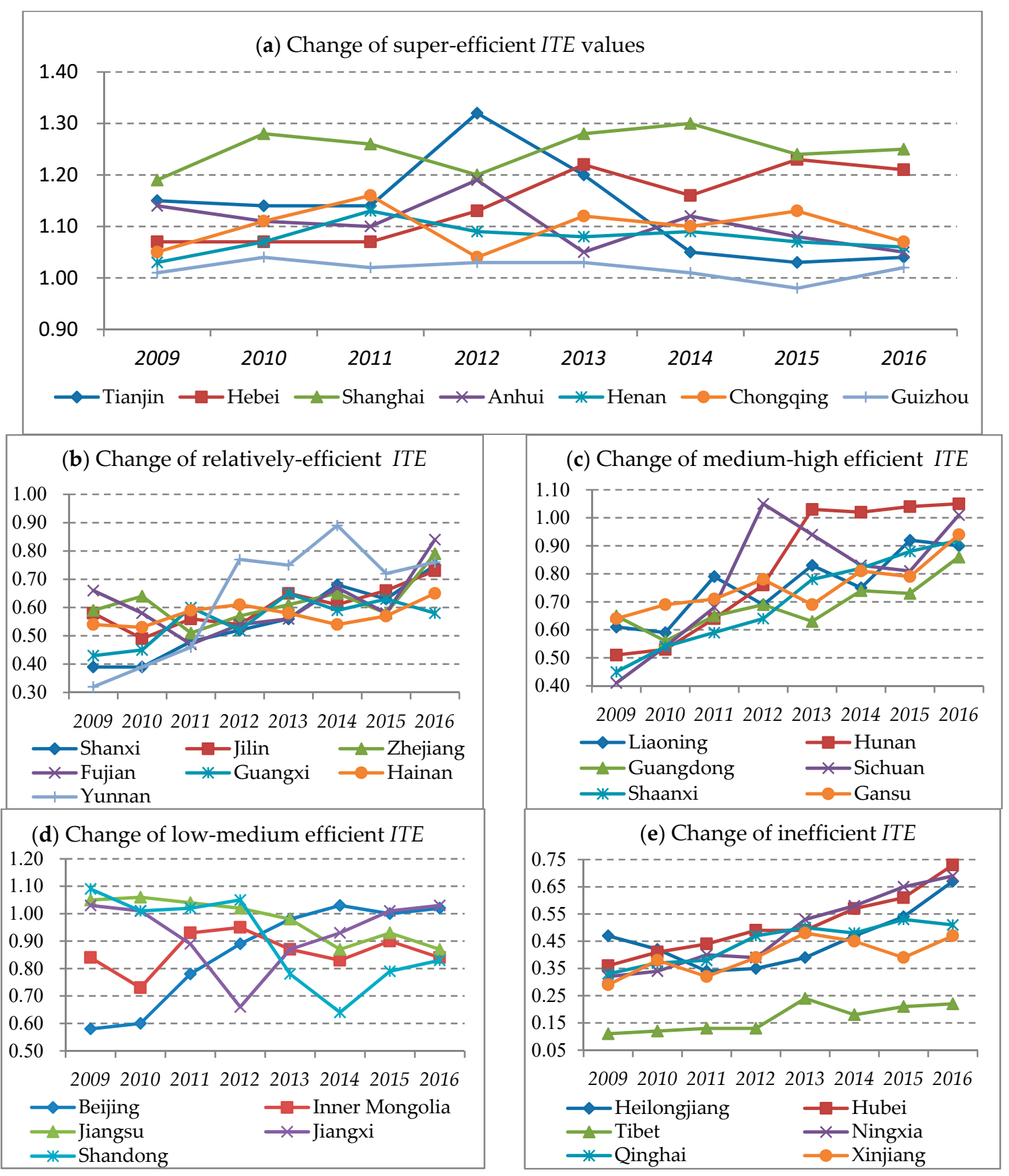

Figure 4. Changes of ITE for each province.

In addition, by calculating the average integrated transport efficiency of these 31 provinces during 2009-2016, it was found that the highest average transport efficiency (Shanghai) was 1.08 times greater than the lowest (Tibet). We then further compared and analyzed the ITE of three key economic zones of China, in line with the administrative division of the 31 provinces (Figure 5).

As shown in Figure 6, the ITE average of three zone shows that Eastern Zone > Central Zone > Western Zone, which is in line with the level of economic development and presence of development policies in the three regions. In general, the ITE values of the Eastern, Central and Western Zone can be seen to be increasing. However, the ITE of Central Zone and Western Zone have a better 
efficiency improvement trend compared to the Eastern Zone. The disparity between the Eastern Zone and Central Zone is gradually shrinking. Changes in the ITE value of the Eastern Zone indicate fluctuations during 2009-2016. The value is close to effective in 2016, which indicates that the use of transport resources in the Eastern Zone is relatively high. In the Central zone, the ITE values fell during 2009-2012 and then r0se from 2012 to 2016, with a growth rate of 28.57\% during 2012-2016. The ITE values of the Western Zone can be seen to increase during 2009-2016.

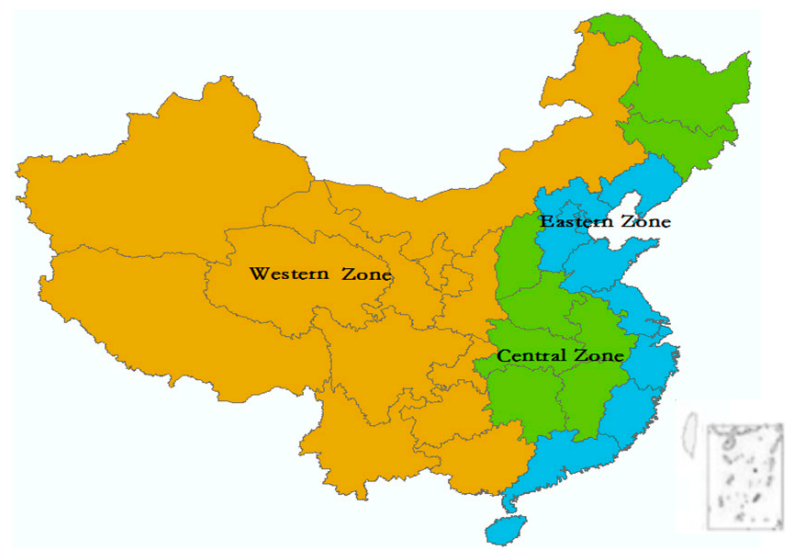

Figure 5. Division of the three economic zones.

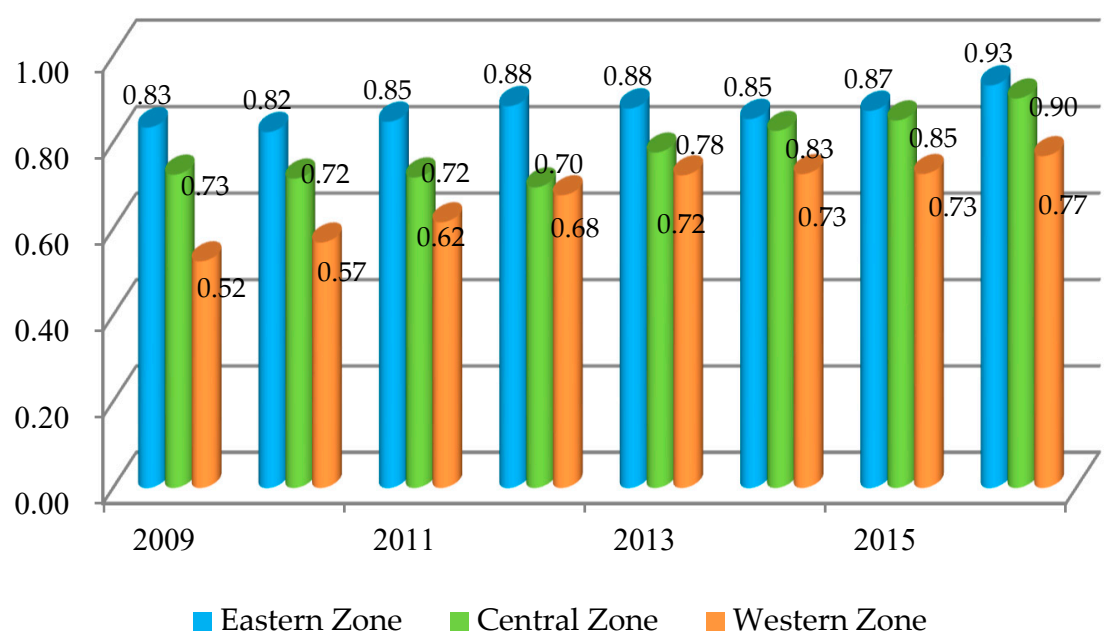

Figure 6. Changes of ITE in the three economic regions during 2009-2016.

\subsubsection{Spatial Autocorrelation Test and Aggregation Results}

The analysis of spatial autocorrelation based on the Moran's I index formed the basis of our spatial convergence analysis. The Moran's I values, estimated by OpenGeoDa (1.2.0) software, are shown in Table 4. The Moran's I indexes during 2009-2016 were found to be greater than zero, indicating a positive spatial autocorrelation between the integrated transport efficiency of the 31 studied provinces. The relevant statistics ( $Z$ values are all greater than $1.96 ; p$ values are all less than 0.05 ) passed the significance test pertaining to spatial autocorrelation. The Z-test, which rejected the null hypothesis that the spatial distribution of China's provincial transport efficiency presents a completely random distribution, and further demonstrates the correctness of the Moran's I results. Furthermore, the existence of spatial autocorrelation indicates that a spatial econometric model could be used to analyze the extent of the necessity for spatial convergence for regional integrated transport efficiency. The integrated transport efficiency of the 31 studied provinces demonstrates significant spatial agglomeration characteristics, indicating that the convergence of integrated transport efficiency that considers spatial effects is both empirically valid and applicable in the current context. In addition, 
the Moran's I Index during 2009-2014 was decreasing, indicating that the spatial autocorrelation of positive transport efficiency weakened over time, and that the interaction between neighboring provinces decreased. However, the value of the Moran's I index gradually increased from 2014 to 2015, with a growing trend of a mutual influence of integrated transport efficiency between adjacent provinces.

Table 4. The calculation results and related statistics of Moran's I index.

\begin{tabular}{cccc}
\hline Year & Moran's I Value & $\boldsymbol{Z}$ Value & $p$ Value \\
\hline 2009 & 0.276 & 2.588 & 0.010 \\
2010 & 0.265 & 2.667 & 0.011 \\
2011 & 0.238 & 2.343 & 0.012 \\
2012 & 0.240 & 2.384 & 0.010 \\
2013 & 0.211 & 2.169 & 0.023 \\
2014 & 0.149 & 1.986 & 0.030 \\
2015 & 0.194 & 1.977 & 0.035 \\
2016 & 0.201 & 2.181 & 0.023 \\
\hline
\end{tabular}

Note: $Z$ statistic and $p$ value were obtained using the Monte Carlo simulation 999 times; the $p$ value is statistically significant at the $5 \%$ level.

According to changes in the Moran's I Index, which were generally experienced during 2009-2016, and taking 2009, 2011, 2014 and 2016 as key nodes containing further significant changes, we analyzed and compared the specific changes and spatial aggregation of China's regional ITE by constructing Moran scatter plots to further understand the spatial distribution characteristics. To clearly show the distribution of each province in the Moran scatter plots, we represent each province by numbering them. As shown in Figure 7, the first quadrant shows provinces with a high level of ITE that are adjacent to other provinces with a high value (H-H aggregation). The second quadrant highlights provinces with a low ITE that are surrounded by provinces with a high level of efficiency, and where the difference in efficiency between neighboring provinces is quite marked (L-H aggregation). The third quadrant illustrates less efficient provinces that are adjacent to other low-value provinces (L-L aggregation). The fourth quadrant shows provinces with a high level of ITE that are bordered by provinces with a lower level (H-L aggregation). In Figure 7, we can see that, in 2009 and 2011, most of the provinces were distributed in the third quadrant and the least were found in the fourth quadrant, indicating that the ITE was mainly characterized by L-L aggregation. Furthermore, the provinces with L-L aggregation features mostly belonged to the western part of China (such as Yunnan (25); Tibet (26); Qinghai (30); Qinghai (31); etc.). However, the points in the third quadrant of 2014 and 2016 show a decreasing trend, which indicated that low-low characteristics of transport efficiency aggregation gradually weakened. In 2014 and 2016, the aggregation features mainly include high aggregation and low aggregation, reflecting a general improvement in ITE and further confirming the spatial aggregation characteristics of China's regional ITE.

To clearly show the changes in the positions of each province's corresponding quadrants at the four time nodes, we summarized the specific changes, as shown in Table 5. Over time, L-L aggregation, such as applying to Jilin, Heilongjiang, Xinjiang and Tibet, occurred in economically underdeveloped border areas, especially in the remote northwestern regions of China. Here, economic development, traffic location and macroeconomic policies tend to lag behind those of the rest of the country, and make these areas have low-value in terms of ITE. In contrast, areas of $\mathrm{H}-\mathrm{H}$ aggregation, such as Beijing, Shanghai and Tianjin, have advantageous conditions that are beneficial to transport development. These regions, therefore, have a relatively high level of ITE. 

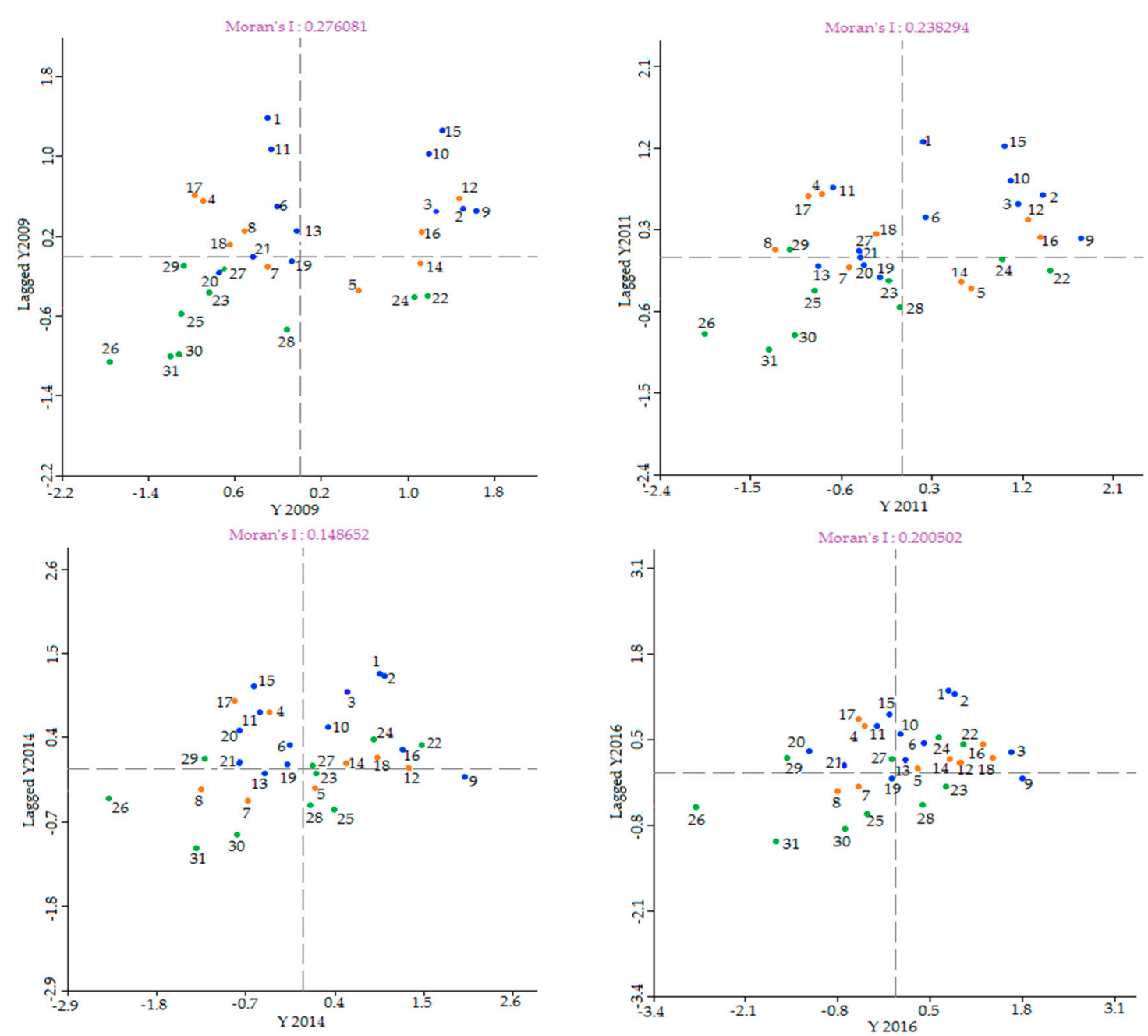

Figure 7. Moran's I scatter graphs of ITEs in China. Note: The provinces are numbered as follows: 1. Beijing; 2. Tianjin; 3. Hebei; 4. Shanxi; 5. Inner Mongolia; 6. Liaoning; 7. Jilin; 8. Heilongjiang; 9. Shanghai; 10. Jiangsu; 11. Zhejiang; 12. Anhui; 13. Fujian; 14. Jiangxi; 15. Shandong; 16. Henan; 17. Hubei; 18. Hunan; 19. Guangdong; 20. Guangxi; 21. Hainan; 22. Chongqing; 23. Sichuan; 24. Guizhou; 25. Yunnan; 26. Tibet; 27. Shaanxi; 28. Gansu; 29. Ningxia; 30. Qinghai; 31. Xinjiang. The provinces represented by blue, orange and green dots are located in the eastern, central and western regions of China, respectively.

Table 5. Changes in corresponding ITE quadrants.

\begin{tabular}{|c|c|c|c|c|}
\hline Year & 2009 & 2011 & 2014 & 2016 \\
\hline $\begin{array}{c}\mathrm{H}-\mathrm{H} \\
\text { aggregation }\end{array}$ & $\begin{array}{c}\text { Tianjin, Hebei, } \\
\text { Shanghai, Jiangsu, } \\
\text { Anhui, Shandong, } \\
\text { Henan }\end{array}$ & $\begin{array}{c}\text { Beijing, Tianjin, } \\
\text { Hebei, Liaoning, } \\
\text { Shanghai, Jiangsu, } \\
\text { Anhui, Shandong, } \\
\text { Henan }\end{array}$ & $\begin{array}{l}\text { Beijing, Tianjin, } \\
\text { Hebei, Jiangsu, } \\
\text { Anhui, Jiangxi, } \\
\text { Henan, Hunan, } \\
\text { Chongqing, } \\
\text { Guizhou, Shanxi }\end{array}$ & $\begin{array}{l}\text { Beijing, Tianjin, Hebei, Jiangxi, } \\
\text { Inner Mongolia, Liaoning, } \\
\text { Anhui, Fujian, Jiangxi, Henan, } \\
\text { Hunan, Chongqing, Guizhou }\end{array}$ \\
\hline $\begin{array}{c}\text { L-H } \\
\text { aggregation }\end{array}$ & $\begin{array}{l}\text { Beijing, Shanxi, } \\
\text { Liaoning, Fujian, } \\
\text { Heilongjiang, } \\
\text { Zhejiang, Hubei, } \\
\text { Hunan, Hainan }\end{array}$ & $\begin{array}{l}\text { Shanxi, Hainan, } \\
\text { Heilongjiang, } \\
\text { Zhejiang, Hubei, } \\
\text { Hunan, Shaanxi, } \\
\text { Ningxia }\end{array}$ & $\begin{array}{l}\text { Shanxi, Liaoning, } \\
\text { Zhejiang, Hubei, } \\
\text { Shandong, Hainan, } \\
\text { Guangdong, } \\
\text { Guangxi, Ningxia }\end{array}$ & $\begin{array}{l}\text { Shanxi, Zhejiang, } \\
\text { Hubei, Shandong, } \\
\text { Guangxi, Hainan, } \\
\text { Shaanxi, Ningxia }\end{array}$ \\
\hline
\end{tabular}


Table 5. Cont.

\begin{tabular}{|c|c|c|c|c|}
\hline Year & 2009 & 2011 & 2014 & 2016 \\
\hline $\begin{array}{c}\text { L-L } \\
\text { aggregation }\end{array}$ & $\begin{array}{c}\text { Jilin, Guangdong, } \\
\text { Guangxi, Tibet, } \\
\text { Yunnan, Sichuan, } \\
\text { Shaanxi, Gansu, } \\
\text { Ningxia, Qinghai, } \\
\text { Xinjiang. }\end{array}$ & $\begin{array}{c}\text { Jilin, Fujian, } \\
\text { Guangdong, } \\
\text { Guangxi, Tibet, } \\
\text { Sichuan, Gansu, } \\
\text { Yunnan, Qingha, } \\
\text { Xinjiang, }\end{array}$ & $\begin{array}{l}\text { Jilin, Henan, } \\
\text { Heilongjiang, } \\
\text { Fujian, Qinghai, } \\
\text { Xinjiang. }\end{array}$ & $\begin{array}{l}\text { Jilin, Yunnan, Tibet, } \\
\text { Heilongjiang, Guangdong, } \\
\text { Qinghai, Xinjiang. }\end{array}$ \\
\hline $\begin{array}{c}\mathrm{H}-\mathrm{L} \\
\text { aggregation }\end{array}$ & $\begin{array}{l}\text { Inner Mongolia, } \\
\text { Jiangxi, Guizhou, } \\
\text { Chongqing, }\end{array}$ & $\begin{array}{l}\text { Inner Mongolia, } \\
\text { Jiangxi, Guizhou, } \\
\text { Chongqing, }\end{array}$ & $\begin{array}{l}\text { Inner Mongolia, } \\
\text { Shanghai, Gansu, } \\
\text { Sichuan, Yunnan. }\end{array}$ & Shanghai, Gansu, Sichuan \\
\hline
\end{tabular}

\subsubsection{Convergence Analysis}

(1) The absolute $\beta$-convergence model selection and result analysis

The aforementioned Moran's I index test demonstrated that there exist clear spatial correlation characteristics in China's ITE. It is now necessary to consider whether an econometric model combining spatial effects can reveal the convergence characteristics of China's regional ITE. Since the space panel model is divided into a fixed effect space panel model and a random effect space panel model, the first test was to determine which type of space panel model should be built in a general study. The results of the Hausman test are generally used to determine whether to use a fixed effect model, to estimate a random effect first, and to test whether to reject the original hypothesis. Then, if a fixed-effect model is decided upon, the time, space or dual fixed effects model need to be established using the likelihood ratio test (LR test). Finally, Lagrange Multiplier tests (LM_Error and LM_Lag) were performed to determine whether the Spatial Lag Model (SLM) or Spatial Error Model (SEM) should be used. The entire process of analysis is shown in Figure 8.

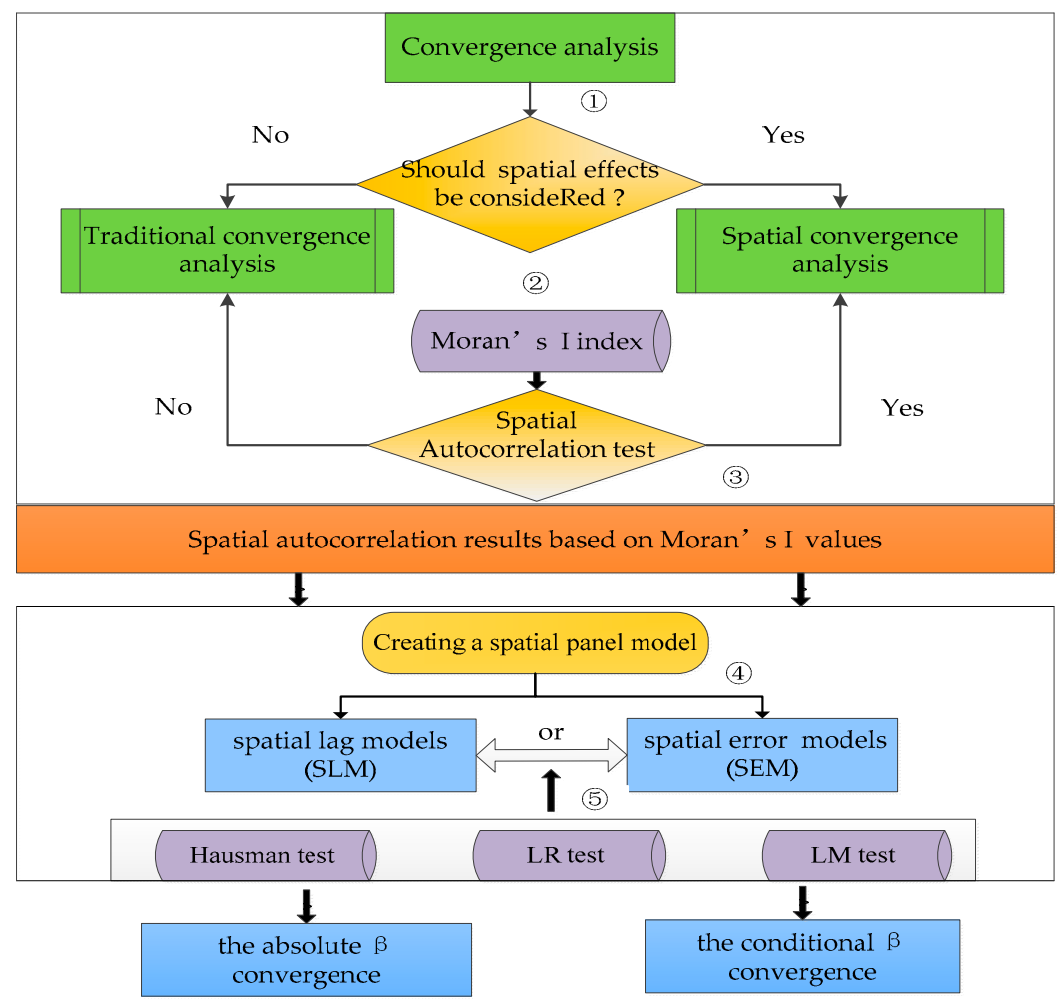

Figure 8. The process of convergence analysis. 
In the current study, the panel data model was tested using Matlab software. The results show the outcome of the Hausman test $(29.175,0.0000)$, the LR test $(514.37,0.0001)$, and that $p$ values are significant at the $5 \%$ level. Thus, a double fixed effect model needed to be established. By conducting the LM_Error and LM_Lag tests, the absolute $\beta$-convergence model of China's regional ITE was then constructed. The test results are shown in Table 6.

Table 6. Spatial correlation tests for the absolute $\beta$-convergence model.

\begin{tabular}{cccc}
\hline $\begin{array}{c}\text { LM_Error } \\
(\boldsymbol{p} \text { Value })\end{array}$ & $\begin{array}{c}\text { Robust LM_Error } \\
(\boldsymbol{p} \text { Value })\end{array}$ & $\begin{array}{c}\text { LM_Lag } \\
(\boldsymbol{p} \text { Value })\end{array}$ & $\begin{array}{c}\text { Robust LM_Lag } \\
(\boldsymbol{p} \text { Value })\end{array}$ \\
\hline 9.263 & 7.381 & 5.279 & 4.814 \\
$(0.023)$ & $(0.0014)$ & $(0.034)$ & $(0.0038)$ \\
\hline
\end{tabular}

Note: The $p$-value is significant at the $1 \%$ level.

In Table 6, it is evident that neither the LM_Error nor the LM_Lag passed the significance test, but that the Robust LM_Error and the Robust LM_Lag passed the significance test. However, by undertaking a numerical comparison, it emerged that the spatial error autocorrelation was more significant than the spatial hysteresis autocorrelation, i.e., the space where the absolute $\beta$-convergence. Since the SEM was found to be better than the SLM, Formula (6) was chosen. The estimated results are shown in Table 7 .

Table 7. Estimation results of the absolute $\beta$-convergence SEM model for ITEs.

\begin{tabular}{|c|c|c|c|c|c|}
\hline $\begin{array}{c}\beta \\
(t \text { Value })\end{array}$ & $\begin{array}{l}\text { Spatial Residual Item } \\
(t \text { Value })\end{array}$ & $\begin{array}{c}\text { Goodness of } \\
\text { Fit }\end{array}$ & $\begin{array}{l}\text { Maximum } \\
\text { Likelihood }\end{array}$ & $\begin{array}{c}\text { Convergence } \\
\text { Speed } \%\end{array}$ & $\begin{array}{l}\text { Half Life } \\
\text { Cycle }\end{array}$ \\
\hline $\begin{array}{l}-0.1057^{* * *} \\
(-4.2603)\end{array}$ & $\begin{array}{c}0.274^{* * *} \\
(2.961)\end{array}$ & 0.768 & 342.191 & 1.39 & 49.8 \\
\hline
\end{tabular}

The maximum likelihood test method was used to estimate the spatial autocorrelation model, as shown in Table 6 . The obtained $\beta$ coefficient was -0.1057 , which is less than zero and passed the $1 \%$ significance test, indicating that there existed a significant, absolute $\beta$-convergence among the regions' ITE during 2009-2016. We could, therefore, further calculate the convergence rate of $1.39 \%$. The goodness-of-fit value indicates that the reliability of the estimation results is high. The spatial residuals passed the $1 \%$ significance test, indicating that there was a positive correlation between the ITE of one province and its neighboring provinces during 2009-2016. Through the empirical analysis, the introduction of the factor of spatial effect was found to have a significant impact on the absolute $\beta$-convergence of regional ITE, indicating that inter-regional connections and cooperation play a crucial role in narrowing the gaps between different regions' ITE. According to the $\beta$-convergence result, the half-life cycle of regional ITE convergence was 49.8 years. It can thus be seen that, although there exist certain convergence characteristics among the regions' ITE, the convergence period takes a long time. Therefore, the provinces with low ITE need to take a long time to catch up to the provinces with high ITE.

(2) The conditional $\beta$-convergence model selection and result analysis

In line with previous studies, this study selected the level of economic development (led), government intervention ( $g i)$, the scale of transport industry development (tids), technological advancement $(t a)$, traffic intensity $(t i)$ and residents' per capita transport consumption expenditure (ptse) as conditional variables that may exert an influence over the convergence of condition $\beta$ in China's regional integrated transport efficiency [3,41,58-60]. Regarding the data processing of these conditional variables, each province's Gross Domestic Product (GDP) was used to express its level of economic development. The ratio of the local government's fiscal expenditure on transport to the gross value of production was used as a proxy to measure the government's degree of intervention in the 
development of the public transport economy. The scale of development of the transport industry was expressed via the ratio of the value added by the transport industry to GDP. Technological progress was mainly reflected in the efficiency of energy use, which was expressed by the ratio of the value added by the transport industry to the amount of energy this industry consumed. These conditional variables were used to show the level of transport technology innovation and application effect of energy saving technology. Transport intensity was expressed as the ratio of conversion turnover to GDP. Residents' per capita transport consumption expenditure reflects the demand for transport. Therefore, as it affects transport outputs, it was also considered as an external factor that may affect integrated transport efficiency.

The statistical descriptions of these indicators are shown in Table 8.

Table 8. Descriptive statistics of conditional variables.

\begin{tabular}{ccccc}
\hline Variable & Min & Max & Mean & Std. dev \\
\hline led & 441.36 & $80,854.91$ & $19,416.23$ & 0.016 \\
$g i$ & 0.005 & 0.124 & 0.021 & 0.027 \\
tids & 0.02 & 0.10 & 0.05 & 0.016 \\
$t a$ & 0.03 & 1.52 & 0.82 & 0.52 \\
$t i$ & 0.04 & 0.96 & 0.29 & 0.17 \\
$p t s e$ & 1993.80 & 3290.60 & 2298.06 & 920.72 \\
\hline
\end{tabular}

Similar to the process of discerning absolute $\beta$-convergence, the condition $\beta$-convergence model of the panel data was checked and estimated using Matlab software. The results are shown in Table 9 .

Table 9. Correlation estimation results of regional ITE convergence.

\begin{tabular}{cccc}
\hline $\begin{array}{c}\text { LM_Error } \\
(\boldsymbol{p} \text { Value })\end{array}$ & $\begin{array}{c}\text { Robust LM_Error } \\
(\boldsymbol{p} \text { Value })\end{array}$ & $\begin{array}{c}\text { LM_Lag } \\
(\boldsymbol{p} \text { Value })\end{array}$ & $\begin{array}{c}\text { Robust LM_Lag } \\
(\boldsymbol{p} \text { Value })\end{array}$ \\
\hline 8.419 & 7.492 & 6.994 & 5.012 \\
$(0.021)$ & $(0.018)$ & $(0.011)$ & $(0.005)$ \\
\hline
\end{tabular}

Note: $p$-values are significant at the $1 \%$ level.

From the spatial diagnosis results in Table 10, we can see that the LM_Error, LM_Lag and Robust LM_Error failed the 1\% significance test, but the Robust LM_Lag passed it, indicating that the SLM established under the condition of the convergence of ITE was more accurate than the SEM. Therefore, the conditional $\beta$-convergence characteristics of ITE were queried using by Formula (7). The estimated results are shown in Table 10.

Table 10. Conditional $\beta$-convergence SLM model estimation and test results.

\begin{tabular}{cccc}
\hline Variable & $\begin{array}{c}\text { Double Fixed Effect } \\
(\boldsymbol{t} \text { Value })\end{array}$ & Variable & $\begin{array}{c}\text { Double Fixed Effect } \\
(\boldsymbol{t} \text { Value })\end{array}$ \\
\hline$\beta$ & $\begin{array}{c}-0.385^{* * *} \\
(-10.429)\end{array}$ & $\ln \mathrm{g} i$ & $\begin{array}{c}-0.118^{* * *} \\
(-3.075)\end{array}$ \\
\hline $\ln l e d$ & $\begin{array}{c}0.102^{* *} \\
(2.163)\end{array}$ & $\ln s i$ & $\begin{array}{c}0.0198^{* *} \\
(0.207)\end{array}$ \\
\hline $\ln t i d s$ & $\begin{array}{c}0.149^{* * *} \\
(3.516)\end{array}$ & $\ln p t s e$ & $\begin{array}{c}0.024^{* *} \\
(2.249)\end{array}$ \\
\hline $\ln t i$ & $\begin{array}{c}0.214^{* * *} \\
(3.843)\end{array}$ & R-squared & 0.784 \\
\hline Adj. $R^{2}$ & 0.318 & Log-likelihood & 658.498 \\
\hline \multicolumn{2}{|c}{ Note: ** and $* * *$ indicate $5 \%$ and $1 \%$ significance levels, respectively. }
\end{tabular}


Using Formula (7) to investigate the results of the spatial lag model of conditional $\beta$-convergence, the result of the $\beta$-convergence emerged as -0.385 . The significance level of $1 \%$ here indicates that there exists a conditional $\beta$-convergence of regional integrated transport efficiency in China. The convergence rate was found to be $6.007 \%$ and $11.41 \%$ for the half-life cycle. Compared with the absolute $\beta$-convergence, after the inclusion of conditional variables, the convergence rate was seen greatly to improve. In the estimation results, the coefficient of government intervention $(g i)$ was negative and passed the $1 \%$ significance test, highlighting a negative correlation between this variable and ITE. This implies that the greater the government's expenditure for transport as a percentage of GDP might make low utilization of capital input and the lower the ITE.

The relationship between the other conditional variables and transport efficiency was found to be positive. Moreover, the level of economic development, household per capita consumption of transport, increase in the size of the transport industry, technological advancement, and increase in traffic intensity were also all seen to have important implications for the convergence of regional integrated transport efficiency. Among them, the promotion of technological advancement emerged as most significant. An increase of $1 \%$ in technological progress means $21.4 \%$ increase in ITE, which is mainly reflected in the greater added value in transport industry in terms of unit energy consumption. Estimates of the scale of development of the transport industry indicate that an increase in output factors will result in significant improvements in ITE. An increase in economic development and per capita household transport consumption will increase transport activities and demand, subsequently promoting the improvement of ITE and changes in convergence characteristics.

\section{Conclusions and Implications}

This study used a super-efficiency data envelopment analysis model with a slack-based measure (Super-SBM DEA), considering undesirable outputs, to measure the integrated transport efficiency of 31 provinces in China in the period 2009-2016. Following this, a spatial autocorrelation analysis was applied to analyze ITE and verify the spatial correlation of ITE in these 31 provinces. Spatial absolute $\beta$-convergence and conditional $\beta$-convergence model were then constructed by further considering spatial effects. Based on this, the convergence characteristics of China's ITE were examined. The study draws the following conclusions.

Overall, the ITE of 31 provinces in China showed varying degrees of growth with the average ITE showing a linear increase. However, the number of effective decision making units (whose value of ITE was found to be greater than 1) was relatively few. By 2016, provinces with efficiency values greater than 1 accounted for about $35 \%$. This indicates that there is much room for adjustment in the amount of investment in transport resources in each province, and that output needs to be improved. The average ITE was expressed as Eastern region > Central region > Western region, which is in line with the level of economic development and the presence of development policies in these three regions. However, from the perspective of future development advantages, the Central Zone and Western Zone have a better efficiency improvement trend compared to the Eastern Zone.

The Moran's I index during 2009-2016 emerged as greater than zero, indicating that there exists a positive spatial autocorrelation in the integrated transport efficiency of the 31 studied regions. The Moran's I index during 2009-2014 was found to be decreasing, indicating that the spatial autocorrelation of positive transport efficiency was weakening, and that the mutual influence between neighboring provinces decreased. However, the Moran's I index gradually increased from 2014 to 2015 with an increasing effect of mutual influence in terms of ITE between adjacent provinces. The existence of spatial correlation proves the correctness of the spatial effect introduced in the convergence analysis and provides a theoretical basis for the choice of the $\beta$-convergence model. The results of the Moran scatter plots constructed to depict the ITE of China's provinces indicate that the spatial aggregation effects are mainly characterized by high-high aggregation, low-high aggregation, and low-low aggregation, while few provinces have high-low aggregation characteristics. 
Through our empirical analysis, the introduction of spatial effects was seen to have a significant impact on the $\beta$-convergence of regional integrated transport efficiency, indicating that inter-regional connections and cooperation play a crucial role in narrowing regional gaps in transport efficiency. While China's regional ITE contains the clear characteristics of both absolute $\beta$-convergence and conditional $\beta$-convergence, it requires a long-term development process. Under the influence of external condition variables, the convergence rate of the conditions was found to be faster than the absolute convergence rate. The level of economic development, per capita household transport consumption, transport industry scale, technological advancement and transport intensity all contributed to the convergence of regional integrated transport efficiency.

Based on this study, some policy recommendations can be put forward for management department. Because the improvement of ITE of each province is a systematic engineering, we should propose some countermeasures from the supply chain view of all the factors which influence the ITE. Therefore, it is necessary to analyze the influence factors from the input and output perspective to increase effective output. For example, the government and transport companies should strengthen traffic safety education to reduce property losses caused by traffic accidents, and pay more attention to reducing carbon emissions from transport through technological innovation and upgrade vehicle emissions standards, especially in Beijing city. Following this, the amount of input resources should be reasonably determined according to the actual output capacity to ensure that the effectiveness of resource utilization. For example, Shaanxi and other provinces are along the Belt and Road, fixed asset investment should be more invested in speeding up the construction of transport hubs and provide conditions for the development of integrated transport. Besides, different provinces should clarify the key points of their own transport efficiency regulation, and formulate development plans according to local conditions. For example, the ineffective provinces such as Hubei should pay attention to the proportion of various modes of transport in the integrated transport system, and improve the effective output of the transport industry by giving full play to the comparative advantages of railway and water freight; the low-medium provinces should further accelerate the optimization and adjustment of transport structure through the upgrades of railway transport and water transport system, and the integration of road transport information resources, especially for Zhejiang and Fujian Provinces; the medium-high provinces such as Guangdong and Hunan Provinces should focus on the transformation and upgrading of the transport industry and strengthen the cooperation with neighboring provinces. In addition, it is necessary to make full use the impact of the spillover effects between provinces to jointly improve the ITE. Finally, from the perspective of the development mechanism, the management department should give full play to the fundamental role of the market mechanism to enhance the integrated transport efficiency.

This study took the integrated transport system as the target for an efficiency measurement model that considers the impact of undesired output, and explores the spatial convergence among 31 provinces. In future research, we will further analyze how these influencing factors affect the convergence of regional ITE and provide some useful measures for narrowing the gaps that emerge. The limitations of this study lie in that the evaluation was carried only from a macro perspective and there was insufficient distinction between technical efficiency and economic efficiency of ITE, which is also a direction of further research.

Author Contributions: For this study, F.M. proposed the idea of this study; F.M. and W.W. jointly organized the structure of this study and established the calculation model; X.L., F.L. and W.W. collected the data and carried out the model calculations; Q.S. and F.L. provided the analysis software; F.M., W.W. and Q.S. analyzed the results and wrote the paper together.

Funding: This research was funded by the National Social Science Foundation of China grant number 18BGL258.

Acknowledgments: We sincerely thank the reviewers for their helpful and constructive suggestions and the editors for their careful and patient work.

Conflicts of Interest: The authors declare that there is no conflict of interests of this paper. 


\section{References}

1. Hadas, Y.; Ranjitkar, P. Modeling public-transit connectivity with spatial quality-of-transfer measurements. J. Transp. Geogr. 2012, 22, 137-147. [CrossRef]

2. Wu, W.; Cao, Y.; Liang, S. Review of transport efficiency and its research trends from the transport geography perspectives. Prog. Geogr. 2013, 32, 243-250.

3. Wu, J.; Ye, G.; Zhong, A. Efficiency Volatility and Influence Factors of Chinese Modern Transportation Industry Based on the Model of Cross-efficiency DEA and VAR. J. Transp. Syst. Eng. Inf. Technol. 2014, $14,8-14$.

4. Woo, S.H.; Pettit, S.J.; Kwak, D.W.; Beresford, A.K.C. Seaport research: A structured literature review on methodological issues since the 1980s. Transp. Res. A Policy 2011, 45, 667-685. [CrossRef]

5. Ruiz, T. Transport efficiency. Transp. Policy 2018. [CrossRef]

6. Kotegawa, T.; Fry, D.; De Laurentis, D.; Puchaty, E. Impact of service network topology on air transportation efficiency. Transp. Res. Part C 2014, 40, 231-250. [CrossRef]

7. Leng, Y.; Kou, C.; Zhou, N.; Li, Q.; Liang, Y.; Xu, Z.; Chen, S. Evaluation on Transfer Efficiency at Integrated Transport Terminals through Multilevel Grey Evaluation. Soc. Behav. Sci. 2012, 43, 587-594. [CrossRef]

8. Palander, T. Environmental benefits from improving transportation efficiency in wood procurement systems. Transp. Res. Part D 2016, 44, 211-218. [CrossRef]

9. Wang, H.; Liu, J.; Liu, K.; Zhang, J.; Wang, Z. Sensitivity analysis of traffic efficiency in restricted channel influenced by the variance of ship speed. Proc. Inst. Mech. Eng. Part M J. Eng. Marit. Environ. 2018, 232, 212-224. [CrossRef]

10. Fei, M.; Xiao, D.L.; Sun, Q.; Liu, F.; Wang, W.; Bai, L. Regional Differences and Spatial Aggregation of Sustainable Transport Efficiency: A Case Study of China. Sustainability 2018, 10, 2399.

11. Barnum, D.T.; Karlaft, M.G.; Tandon, S. Improving the efficiency of metropolitan area transit by joint analysis of its multiple providers. Transp. Res. Part E 2011, 47, 1160-1176. [CrossRef]

12. Carlucci, F.; Cirà, A.; Coccorese, P. Measuring and Explaining Airport Efficiency and Sustainability: Evidence from Italy. Sustainability 2018, 10, 400. [CrossRef]

13. Zhang, L.L.; Wu, W.; Liu, B.Q. Evaluation and analysis of highway transportation efficiency in the Yangtze River Delta based on DEA-Malmquist. J. Univ. Chin. Acad. Sci. 2017, 34, 712-718.

14. Gao, P.; Sun, Z.J.; Lau, Y. Measuring Water Transport Efficiency in the Yangtze River Economic Zone, China. Sustainability 2017, 9, 2278.

15. Joanna, G.; Wysoki'nska, Z. Transport accessibility in light of the DEA method. Comp. Econ. Res. 2014, 17, 55-70.

16. Jain, P.; Cullinane, S.; Cullinane, K. The impact of governance development models on urban rail efficiency. Transp. Res. Part A 2008, 42, 1238-1250. [CrossRef]

17. Peter, W.; Barros, C.P.; Figueiredo, O. Efficiency and productive slacks in urban transportation modes: A two-stage SDEA-Beta Regression approach. Util. Policy 2016, 41, 31-39.

18. Tavassoli, M.; Faramarzi, G.R.; Saen, R.F. Efficiency and effectiveness in airline performance using a SBM-NDEA model in the presence of shared input. J. Air Transp. Manag. 2014, 34, 146-153. [CrossRef]

19. Fu, J.; Jenelius, E. Transport efficiency of off-peak urban goods deliveries: A Stockholm pilot study. Case Stud. Transp. Policy 2018, 6, 156-166. [CrossRef]

20. Dalmo, M.; Peter, W. Brazil's rail freight transport: Efficiency analysis using two-stage DEA and cluster-driven public policies. Socio-Econ. Plan. Sci. 2017, 59, $26-42$.

21. Wua, J.; Zhu, Q.; Chu, J.; Liang, H.L. Measuring energy and environmental efficiency of transportation systems in China based on a parallel DEA approach. Transp. Res. Part D 2016, 48, 460-472. [CrossRef]

22. Correia, E.; Carvalho, H.; Azevedo, S.G.; Govindan, K. Maturity models in supply chain sustainability: A systematic literature review. Sustainability 2017, 9, 64. [CrossRef]

23. Centobelli, P.; Cerchione, R.; Esposito, E. Developing the WH2 framework for environmental sustainability in logistics service providers: A taxonomy of green initiatives. J. Clean. Prod. 2017, 165, 1063-1077. [CrossRef]

24. Bi, G.; Wang, P.; Yang, F.; Liang, L. Energy and Environmental Efficiency of China's Transportation Sector: A Multidirectional Analysis Approach. Math. Probl. Eng. 2014, 2014, 539596. [CrossRef]

25. Liu, H.; Zhang, Y.; Zhu, Q.; Chu, J. Environmental efficiency of land transportation in China: A parallel slack-based measure for regional and temporal analysis. J. Clean. Prod. 2017, 142, 867-876. [CrossRef] 
26. Guanghui, Z.; William, C.; Yixiang, Z. Measuring energy efficiency performance of China's transport sector: A data envelopment analysis approach. Expert Syst. Appl. 2014, 2, 709-722.

27. Song, M.; Zheng, W.; Wang, Z. Environmental efficiency and energy consumption of highway Transportation systems in China. Int. J. Prod. Econ. 2016, 181, 441-449. [CrossRef]

28. Li, G.; Huang, D.; Li, Y. China's input-output efficiency of water-energy-food nexus based on the Data Envelopment Analysis (DEA) model. Sustainability 2016, 8, 927. [CrossRef]

29. Bian, Y.; He, P.; Xu, H. Estimation of potential energy saving and carbon dioxide emission reduction in China based on an extended non-radial DEA approach. Energy Policy 2013, 63, 962-971. [CrossRef]

30. Yang, Q.; Wan, X.; Ma, H. Assessing green development efficiency of municipalities and provinces in China integrating models of super-efficiency DEA and Malmquist index. Sustainability 2015, 7, 4492-4510. [CrossRef]

31. Menegaki, A.N. Growth and renewable energy in Europe: Benchmarking with data envelopment analysis. Renew. Energy 2013, 60, 363-369. [CrossRef]

32. Jia, S.; Wang, C.; Li, Y. The urbanization efficiency in Chendu City: An estimation based on a three-stage DEA model. Phys. Chem. Earth 2017, 101, 59-69. [CrossRef]

33. Chang, Y.T.; Zhang, N.; Danao, D.; Zhang, N. Environmental efficiency analysis of transportation system in China: A non-radial DEA approach. Energy Policy 2013, 58, 277-283. [CrossRef]

34. Centobelli, P.; Cerchione, R.; Esposito, E. Environmental Sustainability and Energy-Efficient Supply Chain Management: A Review of Research Trends and Proposed Guidelines. Energies 2018, 11, 275. [CrossRef]

35. Zhou, P.; Ang, B.W. Linear programming models for measuring economy-wide energy efficiency performance. Energy Policy 2008, 38, 2911-2916. [CrossRef]

36. Xin, D.; Cen, Y.; Lu, A. DEA Model-Based Efficiency Analysis for Road Transport of China's 31 Provinces. J. Transp. Syst. Eng. Inf. Technol. 2011, 6, 25-29.

37. Li, J.; Zuo, Y. Evaluation and analysis of highway transportation efficiency based on supper-efficiency DEA method. J. Transp. Inf. Saf. 2015, 1, 127-132.

38. Wu, Q.; Song, J.; Ju, P.; Bao, X.; Du, K. Spatial Distribution of Provincial Integrated Transport Efficiency in China. Econ. Geogr. 2015, 35, 43-49.

39. Meng, F.; Liu, G.; Yang, Z.; Casazza, M.; Cui, S.; Ulgiati, S. Energy efficiency of urban transportation system in Xiamen, China. An integrated approach. Appl. Energy 2017, 186, 234-248. [CrossRef]

40. Fuglestvedt, J.; Berntesn, T.; Myhre, G.; Rypdal, K.; Skeie, R.B. Climate forcing from the transport sectors. Proc. Natl. Acad. Sci. USA 2007, 105, 454-458. [CrossRef] [PubMed]

41. Wei, J.; Xia, W.; Guo, X.; Marinova, D. Urban transportation in Chinese cities: An efficiency assessment. Transp. Res. Part D 2013, 23, 20-24. [CrossRef]

42. Tao, L.; Wenyue, Y.; Xiaoshu, C.; Zhang, H. Evaluating the impact of transport investment on the efficiency of regional integrated transport systems in China. Transp. Policy 2016, 45, 66-76.

43. Yang, L.J.; Wei, W.; Su, Q.; Jiang, X.; Wei, Y. Evaluation of road transport efficiency in China during1997-2010 based on SBM-undesirable model. Prog. Geogr. 2013, 32, 1602-1611.

44. Li, J.; Huang, X.; Yang, H.; Chuai, X.; Wu, C. Convergence of carbon intensity in the Yangtze River Delta, China. Habitat Int. 2017, 60, 58-68. [CrossRef]

45. Xiao, Z.; Du, X.; Wu, C. Regional Difference and Evolution and Convergence of Innovation Capability in China: Research on Space and Factorial Levels. Sustainability 2017, 9, 1644. [CrossRef]

46. Qin, C.; Ye, X.; Liu, Y. Spatial Club Convergence of Regional Economic Growth in Inland China. Sustainability 2017, 9, 1189. [CrossRef]

47. Hao, Y.; Peng, H. On the convergence in China's provincial per capita energy consumption: New evidence from a spatial econometric analysis. Energy Econ. 2017, 68, 31-43. [CrossRef]

48. Charnes, A.; Cooper, W.W.; Rhodes, E. Measuring the efficiency of decision making units. Eur. J. Oper. Res. 1978, 2, 429-444. [CrossRef]

49. Tone, K. A slacks-based measure of efficiency in data envelopment analysis. Eur. J. Oper. Res. 2001, 130, 498-509. [CrossRef]

50. Song, M.; Zhang, L.; An, Q.; Wang, Z.; Li, Z. Statistical analysis and combination forecasting of environmental efficiency and its influential factors since China entered the WTO: 2002-2010-2012. J. Clean. Prod. 2013, 42, 42-51. [CrossRef] 
51. Anderson, P.; Petersen, N.C. A procedure for ranking efficient units in data envelopment analysis. Manag. Sci. 1993, 39, 1261-1264. [CrossRef]

52. Parent, O.; LeSage, J.P. Spatial dynamic panel data models with random effects. Reg. Sci. Urban Econ. 2012, 42, 727-738. [CrossRef]

53. Ma, F.; Wang, W.L.; Sun, Q.P.; Liu, F.; Li, X.D. Ecological Pressure of Carbon Footprint in Passenger Transport: Spatio-Temporal Changes and Regional Disparities. Sustainability 2018, 2, 317.

54. Zhang, T.L.; Lin, G. On Moran's I coefficient under heterogeneity. Comput. Stat. Data Anal. 2016, 95, 83-94. [CrossRef]

55. National Bureau of Statistics of the People's Republic of China. China Statistical Yearbook; China Statistics Press: Beijing, China, 2009-2016.

56. National Statistics Bureau Energy Statistics Division. China Energy Statistics Yearbook; China Statistics Press: Beijing, China, 2009-2016.

57. Li, J.; Jing, M.T.; Yuan, Q.M. Estimation of carbon emission and driving factors in Beijing-Tianjin-Hebei traffic under green development. J. Arid Land Resour. Environ. 2018, 7, 36-42.

58. Cai, J. Analysis of Influence Factors of Road Transportation Demand Based on Bayesian Structural Equation Model. Chin. J. Manag. Sci. 2015, s1, 386-390.

59. Yuan, C.W.; Zhang, S.; Jiao, P.; Wu, D. Temporal and spatial variation and influencing factors research on total factor efficiency for transportation carbon emissions in China. Resour. Sci. 2017, 39, 687-697.

60. Fang, G.B.; Ma, H.M.; Song, G.J. Analysis of Energy Efficiency and Its Influence Factors in China's Transportation-Based on the Three-phase DEA and GWR Methods. Stat. Inf. Forum 2016, 11, 59-67.

(C) 2018 by the authors. Licensee MDPI, Basel, Switzerland. This article is an open access article distributed under the terms and conditions of the Creative Commons Attribution (CC BY) license (http:/ / creativecommons.org/licenses/by/4.0/). 